\title{
Variabilidade Pluviométrica no Ceará e suas Relações com o Cultivo de Milho, Feijão-Caupi e Mandioca (1987-2016)
}

\author{
Tarcísio Souza Vasconcelos ${ }^{1}$ (D), João Gutemberg Leite Moraes ${ }^{1}$, José Maria Brabo Alves ${ }^{1}$, \\ Silvio Gentil Jacinto Júnior ${ }^{1}$, Laís Lacerda Brasil de Oliveira ${ }^{1}$, Emerson Mariano da Silva ${ }^{1}$, \\ Geocleber Gomes de Sousa ${ }^{2}$ \\ ${ }^{1}$ Mestrado em Climatologia e Aplicações nos Países da CPLP, Universidade Estadual do Ceará, \\ Fortaleza, CE, Brasil. \\ ${ }^{2}$ Universidade da Integração Internacional da Lusofonia Afro-Brasileira, Redenção, CE, Brasil.
}

Recebido em: 30 de Abril de 2019 - Aceito em: 12 de Julho de 2019

\begin{abstract}
Resumo
Este estudo apresenta uma análise da produção agrícola e suas relações com as secas no Ceará na produção agrícola de milho (Zea mays L.), feijão-caupi (Vigna unguiculata L. Walp.) e mandioca (Manihot esculenta Crantz), para o período de 1987-2016. Foram analisadas as variáveis de produção, rendimento e área plantada dessas culturas acompanhados de dados estatísticos, como médias, desvios padrões e coeficientes de variação desses cultivos. Uma ênfase foi dada ao período concomitante de secas entre 2011-2016. Foram coletados dados de precipitação diária (acumulados de 24 horas) em 220 pluviômetros no estado do Ceará, a variabilidade pluviométrica, expressa pelo cálculo de períodos de estiagens (menor ou igual a $2 \mathrm{~mm} \cdot \mathrm{dia}^{-1}$ entre 01 de fevereiro e 31 de maio) chamados de veranicos, que estão associados a esses anos de secas e às características de produção e rendimentos das culturas de sequeiro. No período analisado neste estudo (1987-2016) verificou-se influência direta das anomalias de chuva sobre a produtividade das culturas estudadas, pela incidência de veranicos, com destaque para os anos de 2011 a 2016.
\end{abstract}

Palavras-chave: Clima, Cultivos, agricultura de sequeiro.

\section{Rainfall Variability in Ceará and its Relations with Corn Crop, Cowpea and Cassava (1987-2016)}

\begin{abstract}
This study presents an analysis of agricultural production and its relationship with drought in Ceará in the agricultural production of maize (Zea mays L.), cowpea (Vigna unguiculata L. Walp.) and cassava (Manihot esculenta Crantz) for the period of 1987-2016. The variables production yield and planted area of these crops were analyzed. Statistics, such as means, standard deviations and coefficients of variation of these crops. Emphasis was given to the concomitant period of droughts between 2011-2016. Data were collected from daily precipitation (accumulated 24 hours) in 220 pluviometers in the state of Ceará, the rainfall variability, expressed by the calculation of drought periods (less than or equal to $2 \mathrm{~mm} \mathrm{day}^{-1}$ between February 1 and May 31) associated with these dry years and the yield and yield characteristics of rainfed crops. In the period analyzed in the present study (1987-2016) there was a direct influence of the rainfall anomalies, on the productivity of the studied crops, by the incidence of summer, with highlight for the years 2011 to 2016.
\end{abstract}

Keywords: Climate, Crops, rainfed agriculture.

\section{Introdução}

As culturas do milho, feijão-caupi e mandioca têm relevante importância socioeconômica em todas as regiões do Brasil e podem ser utilizadas na alimentação humana e animal (Devide et al., 2009; Freire Filho et al., 2011; Ferreira et al., 2015).

Autor de correspondência: Tarcísio Souza Vasconcelos, tarcisio.vasconcelos@creace.org.br. 
Áreas vulneráveis do ponto de vista de variabilidades pluviométricas interanuais como o Semiárido Nordeste do Brasil (NEB), sempre terão atividades como a agricultura de sequeiro que dependem da oferta de água proveniente da estação chuvosa evidenciando atividades de alto risco quanto a produção e o rendimento (Alves et al., 2009). As culturas de sequeiro, sobretudo as de ciclo curto são as mais afetadas.

Atualmente é consenso científico que atividades agrícolas dependem da oferta e demanda de água. Os principais fatores que tem relação direta com anos de maior ou menor irregularidade de precipitação no NEB são os fenômenos El Niño e La Niña e os gradientes meridionais, norte sul ou sul norte, positivos ou negativos de anomalias de Temperatura da Superfície do Mar (TSM) no Atlântico Tropical (Hastenrath, 2012; Andreoli et al., 2012, Rodrigues e Mcphaden, 2014, Marengo et al. 2016). O dipolo positivo caracteriza-se com o predomínio de anomalias positivas no Atlântico Tropical Norte e negativas no Atlântico Tropical Sul. Para o dipolo negativo de anomalias de TSM essas características são contrárias em ambas as bacias (Alves et al. 2009).

Em Marengo et al. (2018), foram abordadas as causas do período de secas no NEB entre 2011-2016. As principais causas segundo os resultados desses autores foi o acoplamento de uma sequência de El Niños no Pacífico Tropical que através da conexão chamada ponte atmosférica (Atmospheric Bridge - Nobre e Shukla, 1996) induziu anomalias de TSM positivas no Atlântico Tropical Norte. Essas características, em geral, estão associadas às condições de secas no NEB ou anos de chuvas muito irregulares nas escalas espaciais e temporais.

O estudo de Alves et al. (2009) mostrou que as condições térmicas, associadas à anos de El Niño, La Niña e de gradientes meridionais de TSM nos oceanos Pacífico e Atlântico Tropicais, condicionam anos com mais ou menos produção e produtividade de milho (Zea mays L.), feijão-caupi (Vigna unguiculata L. Walp.) e mandioca (Manihot esculenta Crantz), além de proporcionarem melhores condições de preço a esses cultivos e maior rotatividade econômica no interior do estado do Ceará.

O período de estiagem durante os anos de 2011 a 2016 foi um dos maiores registrados nos últimos anos no Nordeste. Dezenas de rios e açudes já secaram e a produção agrícola que abastece o Ceará e quase todos os outros estados do Nordeste foi reduzida.

O Governo Federal, em função dessa estiagem prolongada, teve ou está periodicamente enviando toneladas de grãos de milho para ajudar na alimentação do gado que morre de fome. Soma-se a isso a temperatura que aumenta gradativamente. Nas cidades do interior do estado do Ceará, a sensação é muito quente devido a geografia que isola o semiárido cearense.

O Ceará é uma região envolta de serras e chapadas, o que impede que as massas de ar frio cheguem ao sertão pelo interior provocando a aridez, que em anos de irregularidade pluviométrica aumenta o risco de melhores produções e rendimentos de culturas de subsistência. Convém Sena (2017) destacar que dos 184 municípios do Estado, 160 já declararam em 2016 estado de emergência, devido à forte escassez de água. Relacionado a essa questão, em regiões semiáridas do mundo, o problema continua não sendo somente a falta de recursos naturais, mas também de uma política coerente de distribuição desses volumes (Transposição do Rio São Francisco), para atendimento de suas necessidades básicas.

Salienta-se que ainda ocorre escassez de estudos de avaliação dos últimos 30 anos de alguns cultivos de agricultura de sequeiro no Ceará, assim, o objetivo geral desse estudo é analisar os aspectos da área plantada, produção e produtividade das culturas do milho, feijão-caupi e mandioca no período de 1987-2016, com ênfase aos anos de 2011 a 2016 no estado do Ceará; investigar como as características dos cultivos estão relacionadas a variabilidade pluviométrica intrassazonal no Estado do Ceará, no período estudado e identificar as características do rendimento desses cultivos agrícolas com eventos de veranicos de cinco dias no Estado entre os meses de fevereiro a maio.

\section{Materiais e Métodos}

O estado do Ceará está localizado na Região Nordeste do Brasil, e tem por limites o Rio Grande do Norte e Paraíba a leste, o Oceano Atlântico a norte e Nordeste, Pernambuco a sul e Piauí a oeste. O Ceará tem sua área total de $146.348,30 \mathrm{~km}^{2}$, o que corresponde a $1,7 \%$ do território nacional e 9,37\% da área do Nordeste (Meu Ceará, 2012). A área de estudo, o Estado do Ceará, se localiza entre os paralelos de $2,5^{\circ} \mathrm{S}$ e $10^{\circ} \mathrm{S}$ e os meridianos de $34^{\circ} \mathrm{W}$ e $42^{\circ} \mathrm{W}$, onde estão inseridas sete mesorregiões de acordo com o IBGE (2013): Centro Sul, Norte, Metropolitana de Fortaleza, Jaguaribe, Noroeste, Sertões e Sul.

Os indicadores climáticos utilizados para elaboração do zoneamento da cultura da Mandioca foram propostos pela Embrapa Mandioca e Fruticultura (2003); e demonstram as condições ideais, toleráveis e não indicadas para o crescimento e desenvolvimento satisfatório desta espécie. Os dados anuais (1987-2106) de produção, produtividade e área plantada de feijão-caupi, milho e mandioca foram obtidos no site do IBGE (Instituto Brasileiro de Geografia e Estatística), Ematerce (Empresa de Assistência Técnica e Extensão Rural do Ceará) e Embrapa (Empresa Brasileira de Pesquisa Agropecuária).

Para precipitação diária no Ceará (totais acumulados de 24 horas período de fevereiro a maio de 1987 a 2016) foram utilizados os dados coletados em pluviômetros sob banco de dados da Fundação Cearense de Meteorologia e Recursos Hídricos (FUNCEME), acerca da precipitação, para verificar a influência da variabilidade pluviométrica 
sobre a produção das culturas no estado do Ceará. Estes dados de precipitação diária foram interpolados para uma grade regular sobre o Ceará usando o método do quadrado da distância.

A metodologia usada para análises realizadas neste estudo segue os seguintes passos:

a. Plotagens de gráficos de produção, rendimento e área plantada das culturas de mandioca, feijão-caupi e milho (1987-2016);

b. Cálculo de médias aritméticas, desvios padrões e coeficientes de variações das variáveis de produção, área plantada (1987-2016) e rendimento das espécies em estudo;

c. Mensuração das anomalias interanuais (1987-2016) normalizadas pelo desvio padrão (DP) das variáveis de produção, área plantada e rendimento das espécies em estudo (calculadas a partir do valor de rendimento observado no ano menos a média do rendimento (19872016) dividido pelo desvio padrão (1987-2016));

d. Identificação para os três cultivos em análises, quanto aos anos que se configuram de alto, médio e baixo rendimento, cujos valores estão com anomalias calculadas no item c com valores acima de 1DP e abaixo de -1DP;

e. Cálculos de veranicos de 5 dias consecutivos ou não, médios para os anos definidos no item $\mathrm{d}$. Os veranicos foram calculados para o período de 01 de fevereiro a 31 de maio, no qual em geral são feitos os plantios desses cultivos de sequeiro;

f. Cálculo de anomalias de precipitação no Ceará (total de fevereiro a maio) para as composições de anos definidos no item $\mathrm{c}$.

\section{Resultados e Discussões}

\subsection{Estatística da produção, rendimento e área plantada de milho, feijão-caupi e mandioca no estado do Ceará no período de 1987 a 2016.}

Nas Tabela 1, 2 e 3 constam a média, o desvio padrão (DP) e o coeficiente de variação $(\mathrm{CV})$ da produção, rendimento e área plantada do feijão-caupi $(\mathrm{F})$, do milho (Mi), e da mandioca (Ma). Em média a maior produção é do milho em torno de 360.000 t, seguido da produção de feijão-caupi com 144.649,27 t.

A partir dos dados analisados, observa-se que a mandioca apresenta um altíssimo rendimento $682.309,63 \mathrm{t} / \mathrm{ha}$ e o menor foi o do feijão-caupi com

Tabela 1 - Estatística da produção de feijão-caupi no Ceará (1987-2016).

\begin{tabular}{lccc}
\hline & Prod. M (t) & Rend. M (t/ha) & Área M (ha) \\
\hline Média & $359.872,66$ & 604,33 & $588.999,13$ \\
DP & $596.931,63$ & 307,76 & $596.931,63$ \\
CV & 1,66 & 0,51 & 1,01 \\
\hline
\end{tabular}

Tabela 2 - Estatística da produção de milho no Ceará (1987-2016)

\begin{tabular}{lccc}
\hline & Prod. M (t) & Rend. M (t/ha) & Área M (ha) \\
\hline Média & $144.649,27$ & 273,37 & $541.993,38$ \\
DP & $551.772,13$ & 93,38 & $103.419,7$ \\
CV & 3,81 & 0,34 & 0,19 \\
\hline
\end{tabular}

Tabela 3 - Estatística da produção de mandioca no Ceará (1987-2016).

\begin{tabular}{lccc}
\hline & Prod. Ma (t) & Rend. Ma (t/ha) & Área Ma (ha) \\
\hline Média & $89.190,53$ & $682.309,63$ & $8.842,01$ \\
DP & $29.952,95$ & $250.082,38$ & $10.938,05$ \\
CV & 0,34 & 0,37 & 1,24 \\
\hline
\end{tabular}

273,37 t/ha. Desvios padrões mais expressivos que a média foram observados para a produção de feijão-caupi e milho, com o feijão-caupi com mais de quatro vezes superior à média. Coeficientes de variação maiores foram observados para a variável produção de feijão-caupi e milho com valores de 3,81 e 1,66, para as áreas plantadas do milho e mandioca com 1,01 e 1,24, respectivamente.

\subsection{Variabilidade interanual (1987-2016) de produção, rendimento e área plantada de feijão, milho e mandioca e suas anomalias}

Nessa seção faz-se uma análise da variabilidade interanual (1987-2016) da produção, rendimento e área do feijão-caupi (Fig. 1a, 1b e 1c), milho (Fig. 2a, 2b, 2c) e mandioca (Fig. 3a, 3b, 3c) e suas anomalias (valores observados anuais menos as suas médias entre 19872016).

Quanto a produção de feijão-caupi e suas anomalias (Fig. 1a), observa-se que nesses trinta anos de estudo a mesma variou de $50.000 \mathrm{t}$ em 1992, para em torno de 300.000 t no ano seguinte. Há alguns acréscimos de produção em alguns anos de La Niñas (1989, 2005 e 2010), e produções mais baixas em anos de El Niños (2012-2016).

A curva de anomalias da produção do feijão-caupi também qualitativamente teve comportamento similar à de produção. Houve desvios positivos nos anos de chuvas observadas mais regulares nas escalas temporais e espaciais no Estado, como é o caso dos anos de La Niñas, desvios negativos nos anos de menos precipitação e mais irregular na distribuição espacial e temporal como nos anos de El Niños.

Para o rendimento do feijão-caupi a variabilidade interanual e suas anomalias (1987-2016), as características são similares aos observados para a produção. Maiores rendimentos e anomalias positivas em anos de La Niñas e menores com predomínio de anomalias negativas em anos de El Niños a exemplos dos útimos anos (2012-2015). Os maiores rendimentos coincidiram com anos de maiores produções $(2005,2007$ e 2010). 


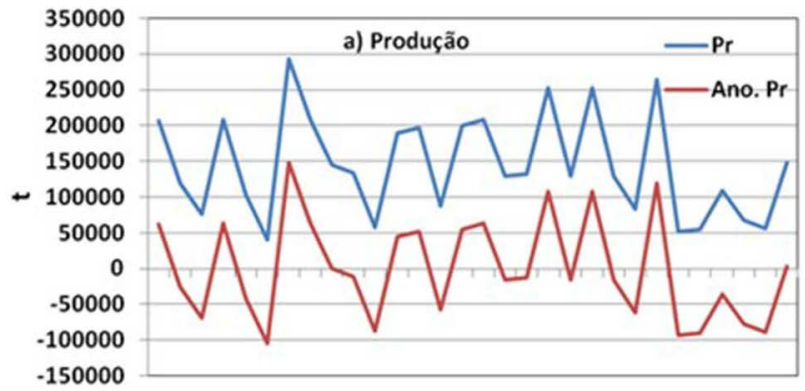

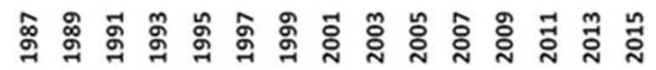
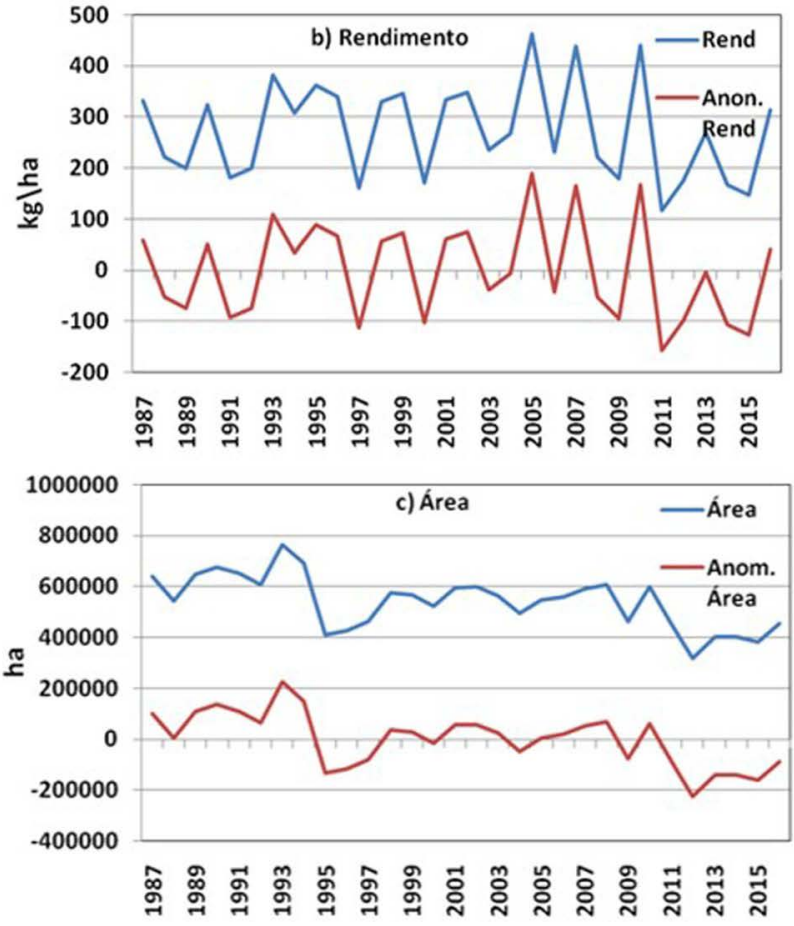

Figura 1 - Produção (t), rendimento $(\mathrm{kg} / \mathrm{ha})$ e área plantada (ha) de feijão-caupi no Ceará (1987-2016).

Em relação a variabilidade interanual essa apresentou valores entre 200.000 ha a próximos de 800.000 ha. Há aparentemente também uma pequena tendência negativa da área a plantada e feijão-caupi do final dos anos 90. Essa característica é evidente nos valores absolutos da área plantada, e se refletiu em suas anomalias com predomínio de anomalias negativas, em particular, a partir de 2010.

Quanto ao cultivo do milho no estado do Ceará (Fig. 2a), diferente do cultivo do feijão-caupi, que é uma cultura de subsídio mais alimentar e não industrial, o milho apresenta uma tendência positiva de produção, embora indicando a influência climática da variabilidade pluviométrica interanual no Estado.

Nota-se com para o feijão-caupi nos anos de La Niña e Normais onde há chuvas mais regulares a produção é maior do que nos anos de El Niños, com maior variabilidade espacial e temporal da precipitação no Estado,

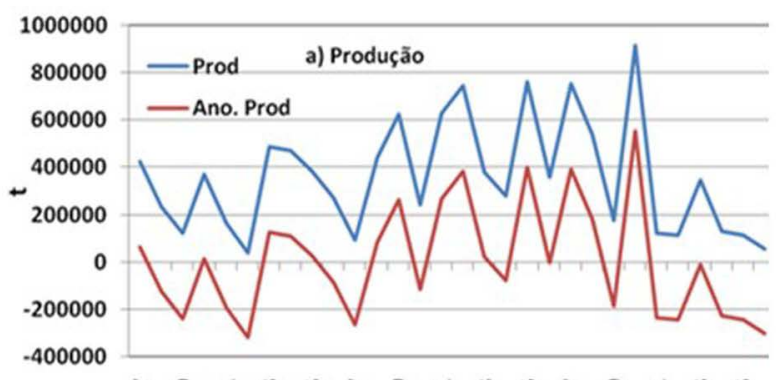

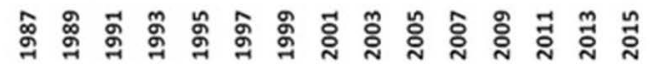
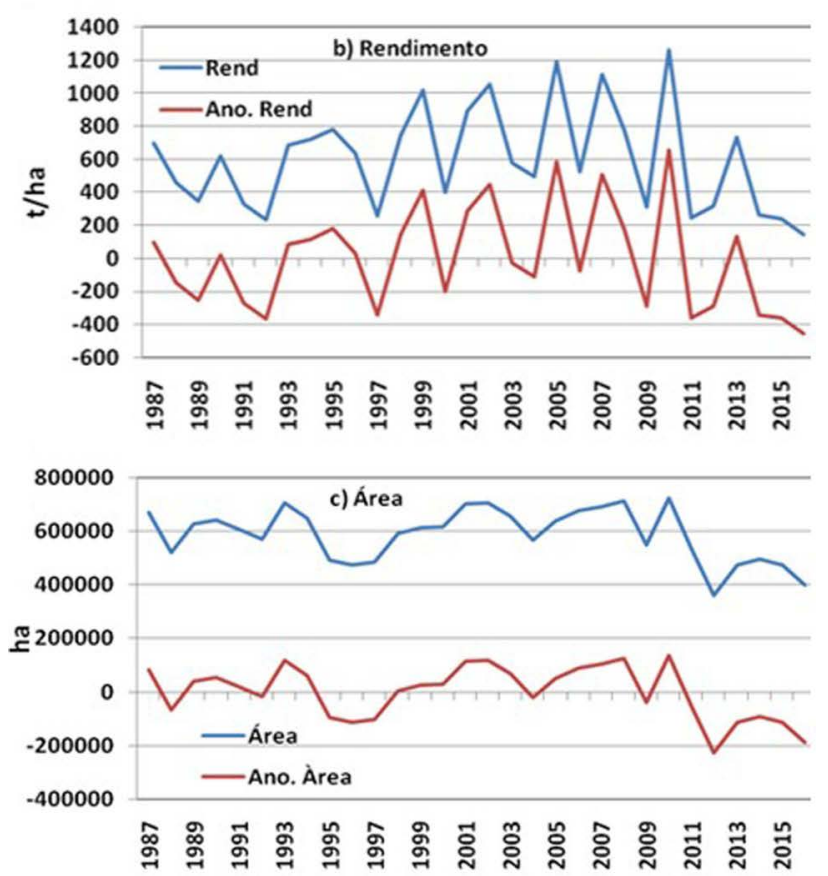

Figura 2 - Produção (t), rendimento (kg/ha) e área plantada (ha) de milho no Ceará (1987-2016).

como já mencionado a exemplo dos anos de 2012-2016. Ressalta-se, a variabilidade interanual da produção de milho, os menores valores são de 2016 abaixo de 200.000 t, há valores próximos a 1.000 .000 t em 2010 .

Houve também períodos em com grande produção entre 1999-2009 que se refletiram nos dados de anomalias, com predomínio de anomalias positivas. O maior período de anomalias negativas na produção de milho foi observado entre 2011-2016, a exceção de 2013. Nos anos 90 alguns anos tiveram baixa produção como o ano de 1993 e 1997. Em alguns anos de La Niña com de 1989 a produção foi baixa diferente da produção de feijão-caupi.

Para o rendimento do milho (Fig. 2b) as características são também similares a produção. A tendência positiva aparece na curva absoluta de valores e suas anomalias, embora menos evidente do que para a produção. Os valores como os de produção comparados ao cultivo do feijão-caupi são bem maiores, oscilaram entre em torno de $200 \mathrm{t} / \mathrm{ha} \mathrm{em}$ 2016, até aproximadamente 1.200 t/ha em 2010. 
Relacionado à variabilidade interanual da área plantada do milho (Fig. 2c), seus valores variaram de 400.000 ha a 800.000 ha. Foi observado também alguns picos máximos e mínimos em torno de três anos que se refletiram na curva de anomalias. Nota-se também, que nesses últimos anos de estiagens/secas seguidas associadas a eventos de El Niños e gradientes meridionais de TSM no Atlântico Tropical não favorável a uma maior regularidade da distribuição de precipitação nas escalas temporais e espaciais nos meses de produção no Estado (Marengo et al. 2018), fevereiro a maio, principalmente; observa-se decréscimo na área plantada e anomalias negativas.

Em relação ao cultivo de mandioca (Fig. 3a), há uma menor variabilidade interanual, e parecem menos controladas pelas variabilidades climáticas da precipitação no Estado. Isso se deve principalmente ao fato dessa cultura se adaptar a diferentes condições climáticas e de solo; e de sua capacidade de tolerar os efeitos deletérios da seca (Johanns e Contiero, 2006).

Embora, que em todas as curvas de valores absolutos e anomalias nesses últimos cinco anos apresentaram valores menores e anomalias negativas, impactos causados devido a influência dos eventos El Niños e gradientes meridionais de anomalias de TSM no Atlântico Tropical não favoráveis à precipitação no Estado.

Tanto para a produção, como para o rendimento (Fig. 3b), ocorreu um período entre 1987-1995 com maior variabilidade e depois uma tendência positiva entre 19952011, quando começou um período de menor rendimento com reflexos em anomalias negativas.

Para área plantada de mandioca (Fig. 3c), as características da variabilidade internual são bem similares a sua produção e rendimento. Não foi observada grande variabilidade em seus valores nesses 30 anos (1987-2016). Há uma pequena variabilidade entre 1987-2005, um pequeno acréscimo entre 1995-2007 e partir desse ano foi observado um predomínio de decréscimo.

A variabilidade interanual da anomalia normalizada pelo desvio padrão anual do rendimento para o feijãocaupi, milho e mandioca no estado do Ceará podem ser observadas na Fig. 4. Dos valores dessas anomalias foram selecionados os anos usados com valores +1DP e inferiores -1DP, para serem calculados os ítem 'd' e 'e' da seção de metodologia. Observa-se que o rendimento dessas culturas de 1987-2016, até 2011, aparentemente tem índicios de tendência positiva. Entretanto, após o ano de 2011, as anomalias tornam-se negativas.

Isso ressalta a influência na variabilidade interanual dos fenômenos térmicos associados as variabilidades das TSM no Oceanos Tropicais que a literaratura tem mostrado no controle de anos mais chuvosos ou secos no semiárido do Nordeste do Brasil (Uvo et. al., 1998; Alves et al., 2009).
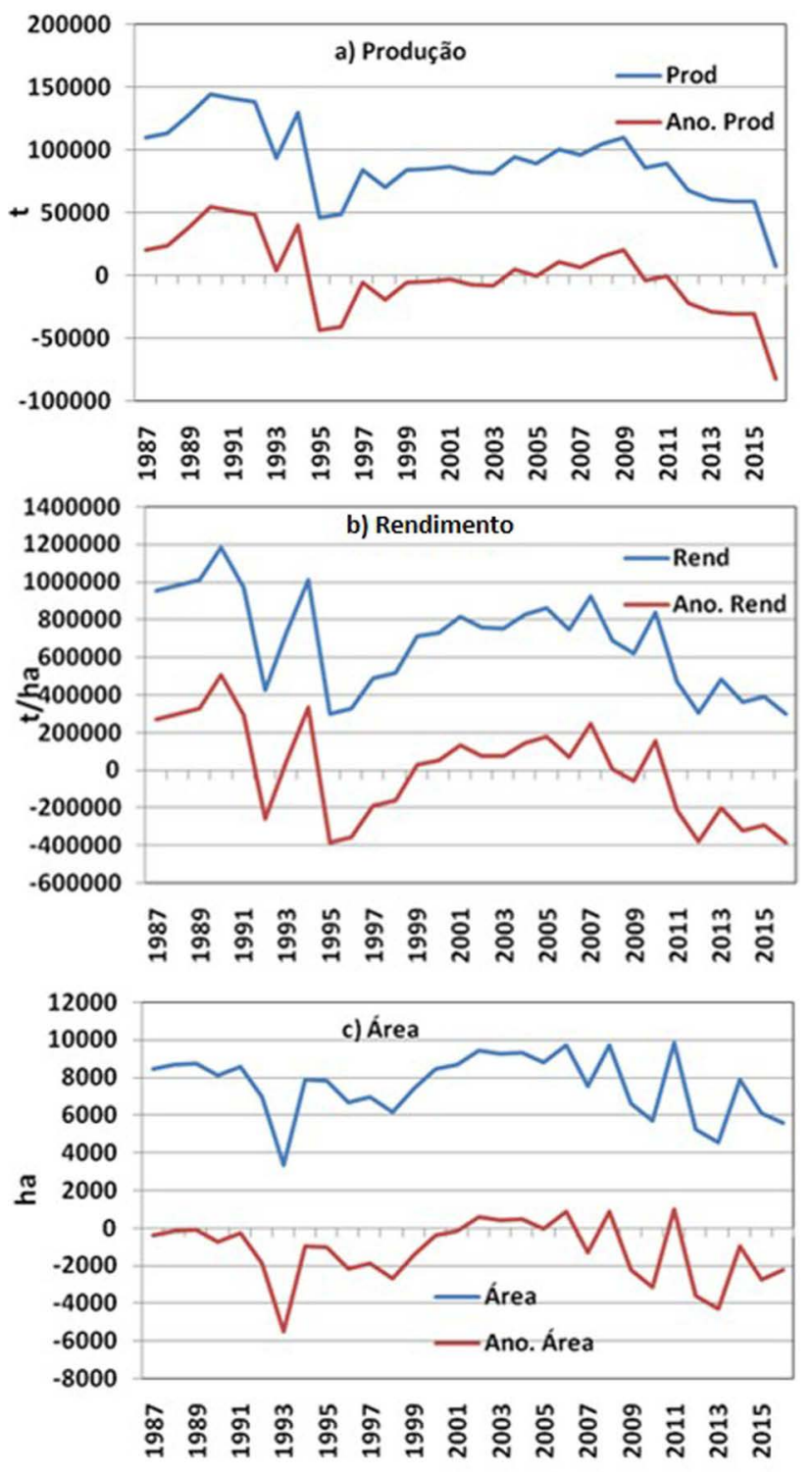

Figura 3 - Produção $(\mathrm{t})$, rendimento $(\mathrm{kg} / \mathrm{ha}) \mathrm{e}$ área plantada (ha) de mandioca no Ceará (1987-2016).

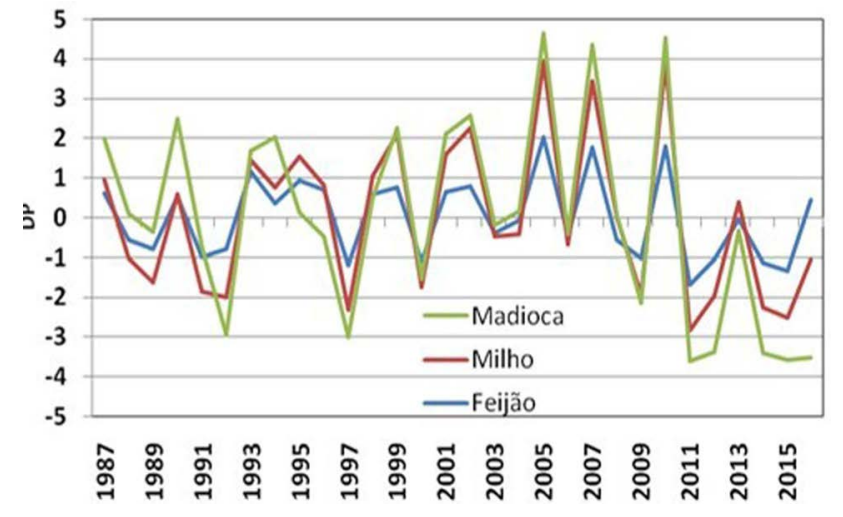

Figura 4 - Anomalia do rendimento normalizada pelo desvio padrão (DP) de milho, feijão-caupi e mandioca no Ceará (1987-2016). 
a)

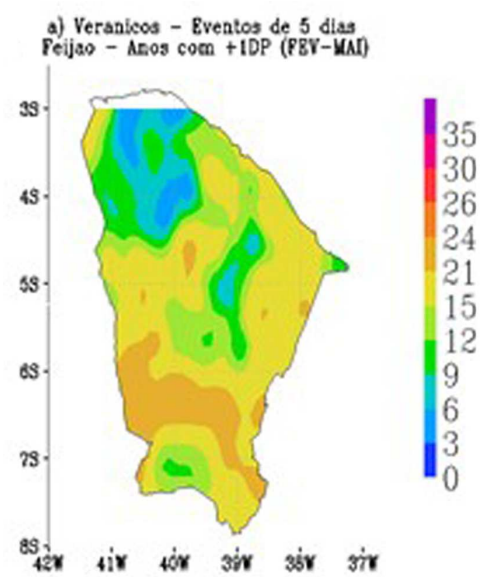

d)

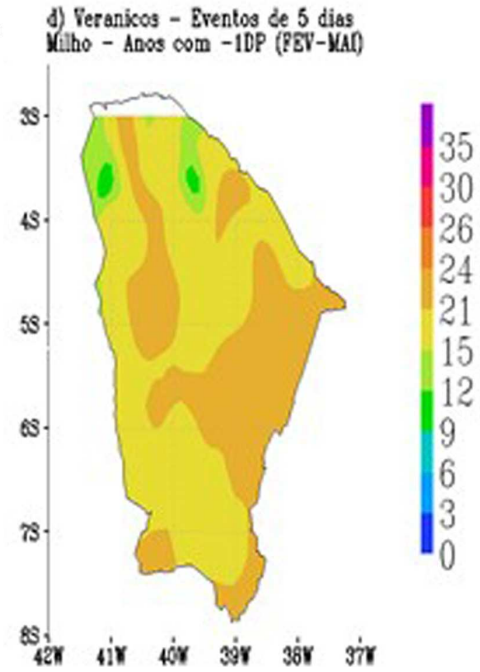

b)

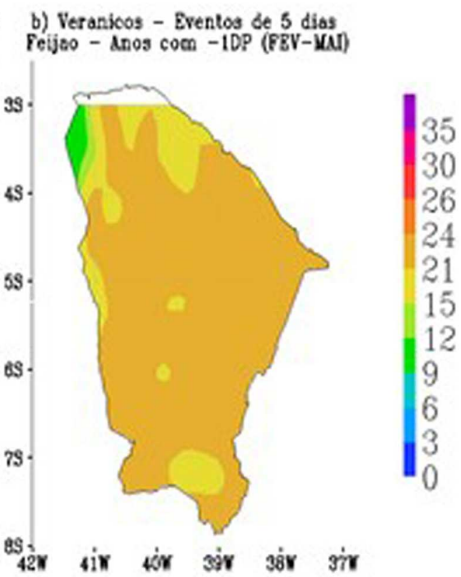

e)

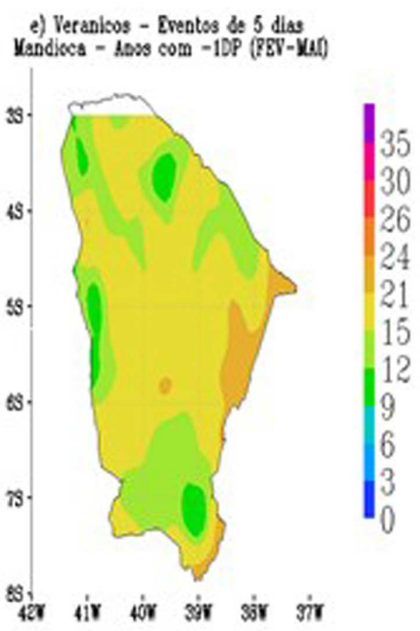

c)

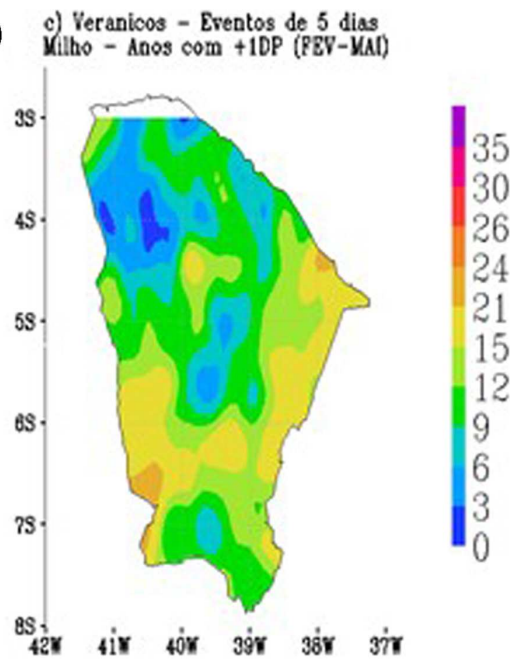

f)

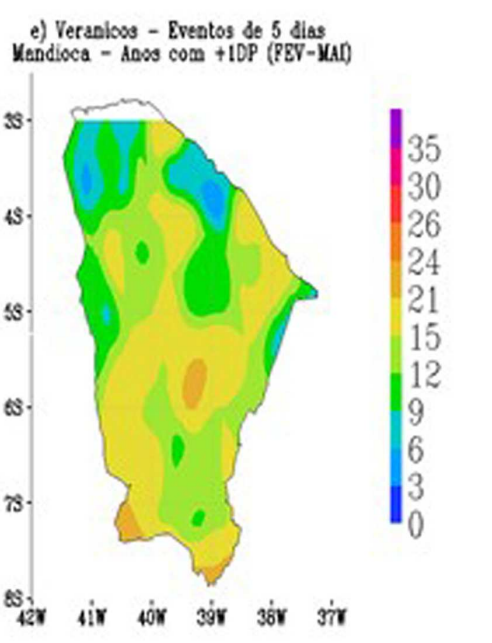

Figura 5 - Número médio de eventos de veranicos de cinco dias para a composição de anos com rendimento +1DP e -1DP (1987-2016). a) Feijão +1DP, b) Feijão -1DP, c) Milho +1DP, d) Milho -1DP, e) Mandioca +1DP e f) Mandioca -1DP.

\subsection{Número de eventos de veranicos médios de 5 dias para os anos de anomalias normalizadas do rendimento das culturas acima e abaixo de 1DP}

Nessa seção são analisados a variação espacial do número médio de eventos de veranicos consecutivos ou não de cinco dias para anos de rendimentos acima e abaixo de 1DP para as culturas de feijão-caupi, milho e mandioca (Fig. 5). Há uma variabilidade do número de eventos de veranicos médios para os anos de desvios padrões maiores e menores que um desvio padrão da curva de rendimentos do feijão-caupi, do milho e da mandioca no estado do Ceará.

Segundo levantamento feito pela Federação dos Trabalhadores na Agricultura do Ceará, localizada na região do Crato, já são 63 municípios que registram veranicos e plantios comprometidos devido a seca verde. Esse valor é equivalente a $34,33 \%$ do total das cidades no Estado do Ceará (Vicelmo, 2010).
3.4. Variabilidade de anomalias de precipitação $(\mathrm{mm})$ para a quadra chuvosa (fevereiro a maio) para os anos de anomalias nornalizadas do rendimento da culturas acima e abaixo de 1DP

A seguir são analisados a variação das anomalias de precipitação (mm) (Fig. 6) para a quadra chuvosa (total de fevereiro a maio) para os anos de rendimentos acima e abaxo de 1DP para as culturas de feijão-caupi, milho e mandioca.

Pode-se observar a variação das anomalias de precipitação $(\mathrm{mm})$ para a quadra chuvosa (total de fevereiro a maio) médios para os anos com rendimentos de desvios padrões maiores e menores que um desvio para o feijãocaupi, do milho e da mandioca no estado do Ceará.

Nota-se para todas as culturas agrícolas ao longo do território cearense que a relação é mais linear com o predomínio negativas de precipitação na quadra chuvosa no Estado quando o rendimento das culturas foi de anos com 
a)

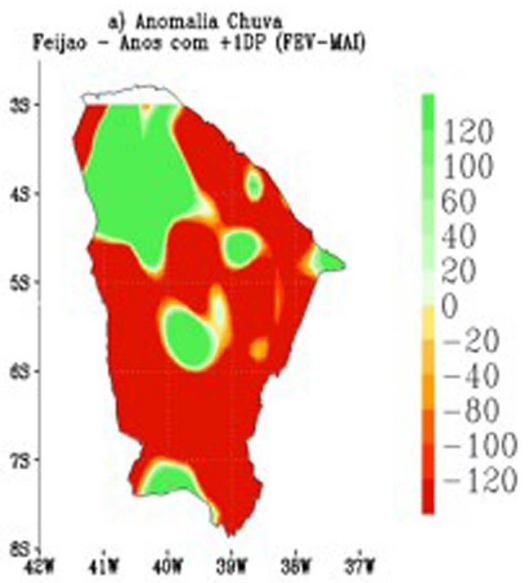

d) Wilto - d) Anomalia Chura

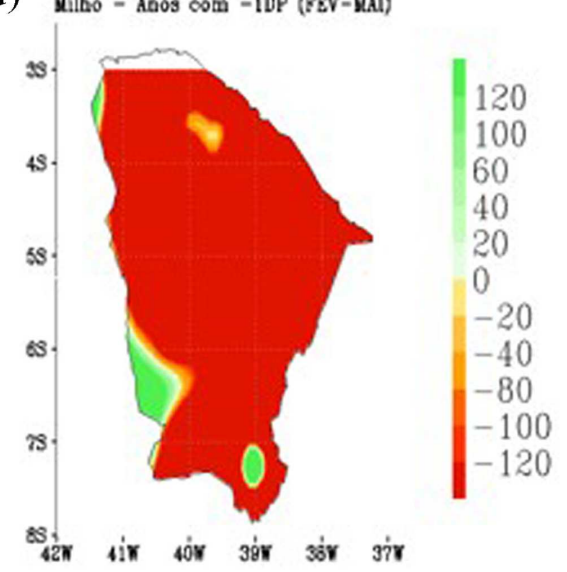

b)

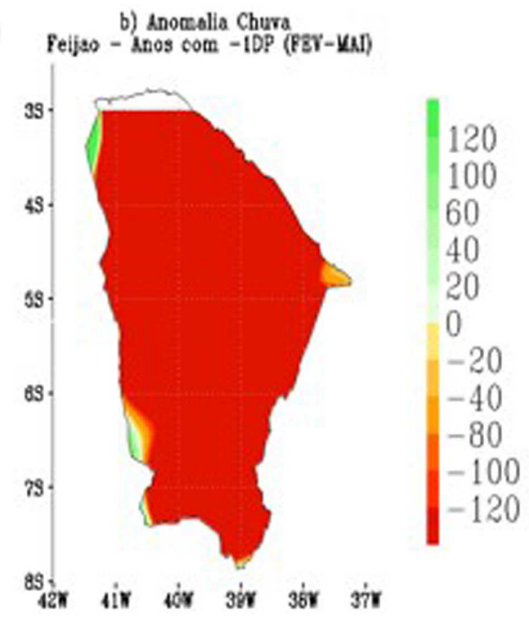

e) (randion Anomallia Chura

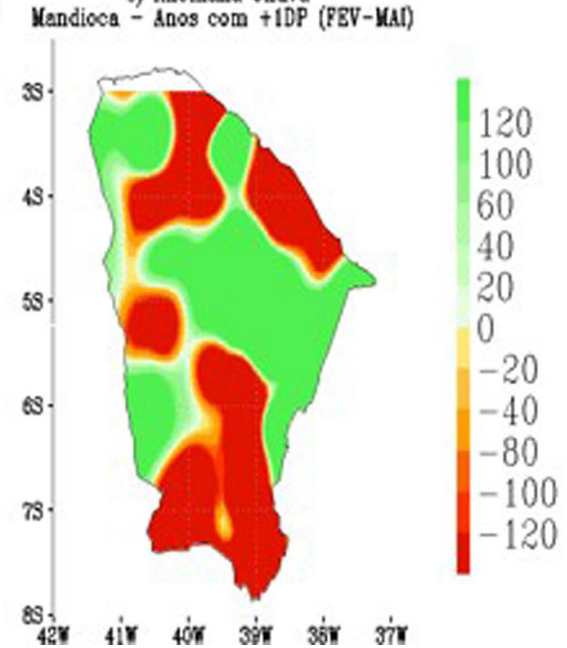

c)

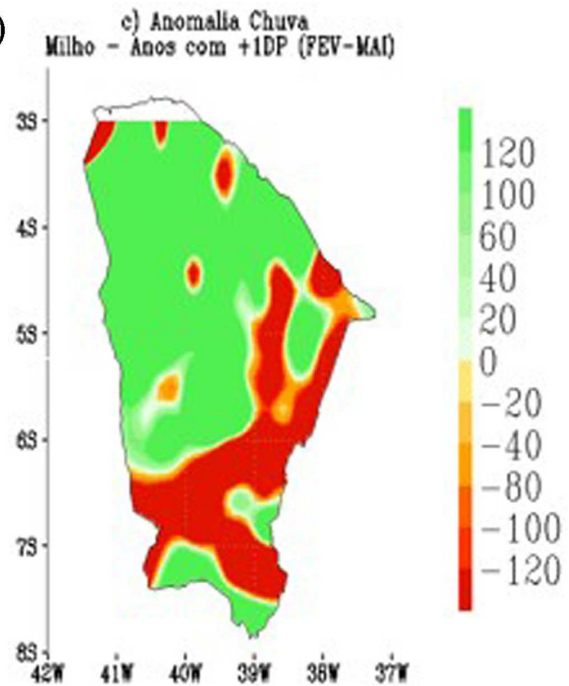

f)

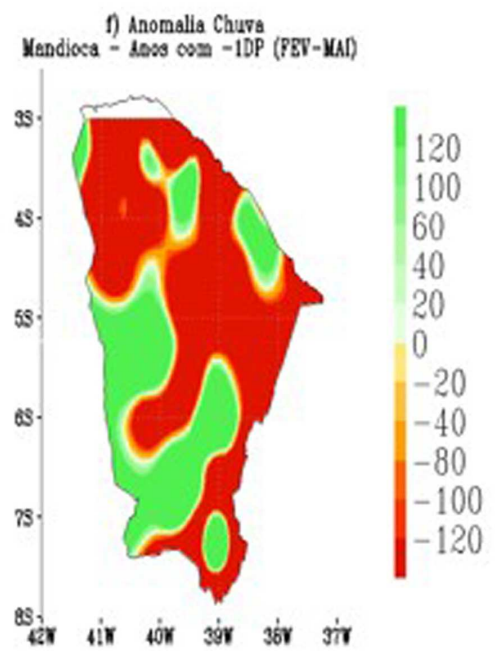

Figura 6 - Anomalias de precipitação (mm) para a quadra chuvosa (Fevereiro a Maio) para a composição de com rendimento +1DP e -1DP (1987-2016). a) Feijão +1DP, b) Feijão -1DP, c) Milho +1DP, d) Milho -1DP, e) Mandioca +1DP e f) Mandioca -1DP.

-1DP. Isto é, quando as culturas estudadas tiveram anos com rendimentos inferiores a $1 \mathrm{DP}$, em grande parte do Estado houve um predomínio de anomalias negativas de precipitação no estado do Ceará, bem evidentes no cultivo do Milho e feijão

Ao contrário, para a composição de anos com rendimentos dessas culturas agrícolas com +1DP, não foi observado uma quadra chuvosa com predominância de anomalias positivas no Estado. Em algumas áreas do Sertão do Estado foram observadas anomalias negativas de precipitação, características mais para anos de secas ou com estiagens. Essa característica é mais marcante para as culturas de feijão-caupi.

\section{Conclusões}

A partir desse estudo pode-se concluir que a precipitação pluviométrica exerce impacto significativo na produção agrícola do Ceará, afetando os parâmetros de área plantada, produção, e produtividade das culturas de feijão caipi, milho e mandioca; aumentando ou reduzindo o seu rendimento médio e influenciando com isso os aspectos agrícolas e socioeconômicos do estado do Ceará.

Ao se analisar as anomalias ocasionadas pelos anos de El Niño e La Niña, observa-se um incremento positivo no rendimento de todas as culturas nos anos de La Niña (ocasionados por maior precipitação pluviométrica no estado do Ceará, com chuvas mais regulares) em comparação com os anos de El Niño onde se constata comportamento oposto.

Quando comparados os números de eventos de veranicos de cinco dias para todas as culturas agrícolas estudadas observou-se uma tendência de redução para os anos com +1DP se comparados aos anos com -1DP. A partir disso, pode-se concluir que essa característica infere mais estiagens ao longo do Estado entre fevereiro a maio em 
anos de menos -1DP de rendimento das culturas influenciando diretamente na produtividade desses cultivos.

Desse modo, os resultados obtidos possibilitam elaborar ações que visam minimizar os efeitos da variabilidade da precipitação na produção dessas culturas agrícolas. A prevenção contra perdas e o monitoramento pluviométrico, é de suma importância para auxiliar no planejamento agrícola, norteando as decisões de plantio e colheita, além de buscar, incentivar e ampliar, implantando sistemas de irrigação, propiciando ganhos na produtividade e gerando melhorias nas condições agrícolas e socioeconômicas dos agricultores do Ceará.

\section{Referências}

ALVES, J.M.B; SERVAIN, J.; CAMPOS, J.B. Relationship between ocean climatic variability and rain-fed agriculture in northeast Brazil. Climate Research, v. 38, n. 5, p. 225236, 2009

ANDREOLI, R.; SOUZA, F.; KAYANO, M.T.; CANDIDO, L. A. Seasonal anomalous rainfall in the central and eastern Amazon and associated anomalous oceanic and atmospheric patterns. International Journal of Climatology, v. 32, n. 8, p. 1193-1205, 2012.

DEVIDE, A.C.P.; RIBEIRO, R.L.D.; VALLE, T.L.; ALMEIDA, D.L.; CASTRO, C.M.; FELTRAN, J. C. Produtividade de raízes de mandioca consorciada com milho e caupi em sistema orgânico. Bragantia, v. 68, n. 1, p. 145-153, 2009.

EMBRAPA Mandioca e Fruticultura - Empresa Brasileira de Pesquisa Agropecuária. Cultivo da Mandioca para o Estado do Pará. Versão eletrônica, 2003. Disponível em: http://sistemasdeproducao.cnptia.embrapa.br/Fon tesHTML/Mandioca/mandioca_para/index.htm. Acesso em: 25 de maio de 2015.

FERREIRA, E.A.; FIALHO, M.T.; BIBIANO, C.S.; BRAGA, R. R.; PEREIRA, G.A.M.; SILVA, D.V.; SANTOS, J.B. Atividade microbiana de solos cultivados com mandioca em sistema de policultivos. Magistra, v. 27, n. 3/4, p. 405-410, 2015.

FREIRE FILHO, F.R.; BARROS, F. R.; ANUNCIAÇÃO FILHO, C.J.; ROCHA, M.M.; NUNES, J.R.; SILVA, K.J.D.; RIBEIRO, V. Q. Potencial genético de progênies de feijãocaupi segregantes quanto ao tipo da inflorescência. Pesquisa Agropecuária Brasileira, v. 46, n. 2, p. 182-189, 2011.

FUNDAÇÃO CEARENSE DE METEOROLOGIA E RECURSOS HÍDRICOS. Gráfico de chuvas dos Postos
Pluviométricos. Disponível em: http://www.funceme.br/? page_id=2702. Acesso em 02 jun. 2019

HASTENRATH, S. Exploring the climate problems of Brazil's Nordeste: a review. Climate Change, v. 112, n. 2, p. 243251, 2012.

INSTITUTO BRASILEIRO DE GEOGRAFIA E ESTATÍSTICA. Cultura do cultivo do nordeste. Brasília: IBGE, 2013. Disponível em: http://www.sidra.ibge.gov.br. Acesso em: 2 abr. 2015.

JOHANNS, O.; CONTIERO, R.L. Efeitos de diferentes períodos de controle e convivência de plantas daninhas com a cultura da mandioca. Revista Ciência Agronômica, v. 37, n. 3, p. 326-331, 2006

MARENGO, J.A.; ALVES, L.M.; ALVALA, R.C.S.; CUNHA, A.P. BRITO, S.; MORAES; O.L.L. Climatic characteristics of the 2010-2016 drought in the semiarid Northeast Brazil region. Anais da Academia Brasileira de Ciências, v. 90, n. 2, p. 1973-1985, 2018.

MARENGO, J.A., TORRES, R.R.; ALVES, L.M. Drought in Northeast Brazil: past, present, and future. Theoretical and Applied Climatology, v. 129, n. 3/4, p. 1189-1200, 2016.

MEU CEARÁ. O Ceará. 2012. Disponível em: http://www.meu ceara.com.br/o-ceara/. Acesso em: 27 jul. 2018.

NOBRE, P.; SHUKLA, J. Variations of sea surface temperature, wind stress, and rainfall over the tropical Atlantic and South America. Journal of Climate, v. 9, n. 10, p. 24642479, 1996.

RODRIGUES, R.R.; MCPHADEN, M.J. Why did the 20112012 La Niña cause a severe drought in the Brazilian Northeast? Geophysical Research Letters, v. 41, n. 3, p. 1012-1018, 2014.

SENA, J.M. Ceará atinge marca de nove milhões de habitantes em 2017, diz IBGE. O Povo, Fortaleza, 31 ago. 2017. Disponível em: https://www.opovo.com.br/jornal/cotidiano/ 2017/08/ceara-atinge-marca-de-nove-milhoes-de-habi tantes-em-2017-diz-ibge.html. Acesso em: 10 maio 2018.

UVO, C.B.; REPELLI, C.A.; ZEBIAK, S.; KUSNHIR, Y. The Relationships between Tropical Pacic and Atlantic SST and Northeast Brazil Monthly Precipitation. Journal of Climate, v. 11, n. 4, p. 551-562, 1998.

VICELMO, A. Seca verde antiga 63 municípios cearenses. Diário do Nordeste, Fortaleza, 04 mar. 2010. Disponível em: http://diariodonordeste.verdesmares.com.br/cadernos/regio nal/seca-verde-atinge-63-municipios-cearenses-1.751137. Acesso em: 27 jul. 2018.

License information: This is an open-access article distributed under the terms of the Creative Commons Attribution License (type CC-BY), which permits unrestricted use, distribution and reproduction in any medium, provided the original article is properly cited. 